\title{
KNOWLEDGE TRANSFER ACROSS DIFFERENT BOUNDARIES IN A PROJECT ENVIRONMENT: A CASE STUDY OF A BOTSWANA MINING ORGANISATION
}

\author{
A. Jhamba ${ }^{1 \#} \&$ H. Steyn ${ }^{1 *}$
}

\section{ARTICLE INFO}

\section{Article details}

Submitted by authors 20 Feb 2020 Accepted for publication 29 Mar 2021 Available online 28 May 2021

\section{Contact details}

Corresponding author herman.steyn@up.ac.za

Author affiliations

1 Department of Engineering and Technology Management, University of Pretoria, South Africa

\# The author was enrolled for an $M$ Eng (Project Management) degree in the Department of Engineering and Technology Management, University of Pretoria, South Africa

\section{ORCID® identifiers}

A. Jhamba

https://orcid.org/0000-0001-6949-1547

H. Steyn

http://orcid.org/0000-0002-5913-6354

DOI

http://dx.doi.org/10.7166/32-1-2326

\section{ABSTRACT}

Effective knowledge transfer is essential in obtaining a competitive advantage. In a project environment, knowledge transfer occurs across different boundaries and involves different stakeholders - a topic much neglected in the literature. This paper explores the processes at play when knowledge is transferred across different boundaries, and then focuses on the role played by the document management system in a project management office. Results from focus group workshops and interviews indicate that the project management office plays a vital role in ensuring effective knowledge transfer, and that the roles differ at different boundaries. In the mining case study, the document management system plays a key role in knowledge transfer.

\section{OPSOMMING}

Effektiewe kennisoordrag is noodsaaklik ter bereiking van 'n mededingende voorsprong. In 'n projek-omgewing vind kennisoordrag plaas oor verskeie grense waarby verskillende belanghebbendes betrokke is - 'n onderwerp wat nog min aandag in die literatuur geniet. Hierdie artikel ondersoek die prosesse ter sprake wanneer kennis oor verskillende grense oorgedra word en fokus dan op die rol van die dokument hanteringstelsel in 'n projekbestuur kantoor. Fokusgroep werkwinkels en onderhoude dui daarop dat die projekbestuur kantoor 'n noodsaaklike rol speel in effektiewe kennisoordrag en dat die rolle by verskillende grense verskil. In die mynbou geval wat bestudeer is, speel die dokumenthanteringstelsel 'n kern rol.

\section{INTRODUCTION}

Organisations currently face globalisation, and competing in the global market requires them to look for opportunities to enhance their competitiveness and improve market share. 'Knowledge management' is defined by Brelade and Harman [1] as the acquisition, sharing, and use of information to generate and develop knowledge, and subsequently to use the knowledge for the benefit of the organisation. Hanisch, Lindner, Mueller and Wald [2] define 'project knowledge management' as the management of knowledge in projects, thus ensuring the link between the principles of project management and knowledge management. According to Sokhanvar, Matthews and Yarlagadda [3], knowledge management is one of the critical factors for project success and organisational performance. However, they also note a significant gap in the literature on knowledge management processes, especially on the role of project management offices (PMOs). According to Hanisch et al. [2], the literature has gone a long way to identifying the challenges and problems of knowledge management in project environments; however, a challenge still exists in developing general solutions, tools, or processes that can be used to manage knowledge in projectbased firms and organisations. Several organisations have set up PMOs in order to improve the delivery of projects; and these PMOs can play different roles depending on the organisation. According to the Project Management Institute [4], the PMO can play the leading role in knowledge management in an organisation. 
This paper reports on an empirical study carried out at a Botswana mining organisation to explore knowledge management in a project environment in a mining organisation. The study focused on a PMO in the organisation, and investigated knowledge transfer (KT) mechanisms across different boundaries, the inhibitors at play, the role of the document management system, and the role of the PMO in KT.

\subsection{Research objectives}

The research focused on establishing the mechanisms of KT across different boundaries and the role of the PMO, explored what hinders KT across the different boundaries, and then focused on the specific role of the document management system in the PMO and its impact on KT. The literature has covered the role of the PMO in general in respect of KT; the aim of this study was to go further and to define this role in the context of different boundaries and the associated inhibitors as perceived by different stakeholders. The document management system emerged as a key inhibitor or enabler of KT in the early part of the study, and this became a focus area for the study - that of investigating the importance of the document management system regarding KT in the PMO.

\section{LITERATURE REVIEW}

\subsection{Knowledge management}

\section{Challenges with knowledge management}

Challenges are noted in respect of reconciling the importance of knowledge management with the actual application of knowledge management, as outlined below. Schindler and Eppler [5], through their research over a period of three years, found that experience and knowledge acquired in different projects are not being managed or integrated properly into knowledge management systems or databases. Nicholas and Steyn [6] emphasised the importance of reviews at project closure and at phase gates; but, according to Kotnour and Vergopia [7], Von Zedtwitz [8], and Keegan and Turner [9], most organisations (from their research samples) do not use post-project reviews as part of knowledge management for projects. Lehtimaki, Simula and Salo [10] showed that, in project organisations, knowledge management is still immature despite the fact that effective and systematic knowledge management is necessary in order to avoid knowledge fragmentation and loss, which inhibits organisational learning.

The literature also indicates that organisations generally face a challenge in the application of knowledge management principles or processes, and especially in project environments. Even organisations that have set up policies and procedures to support the knowledge management process seem to struggle with practical implementation [9].

\subsection{Knowledge transfer}

Knowledge transfer (KT) always involves at least two parties; the sender and the receiver. In some cases, there may be a third party that facilitates or ensures that transfer of the knowledge takes place.

As noted by Tshuma, Steyn and Van Waveren [11], KT is becoming very important for most organisations; it can give an organisation a competitive advantage, and its success is vital for the delivery of project portfolios. However, KT also proves to be very challenging. KT is a process that results in distributing, integrating, interpreting, and applying the know-what, know-how, and know-why embedded in project teams and their members, and ultimately helps to improve the execution of project activities [12]. A key point to note is that knowledge management can only be deemed effective or useful if the transfer occurs and the receiving project benefits from the transferred knowledge [13]. According to Tshuma et al. [11], the PMO can play either a moderating or a mediating role in the transfer of technology.

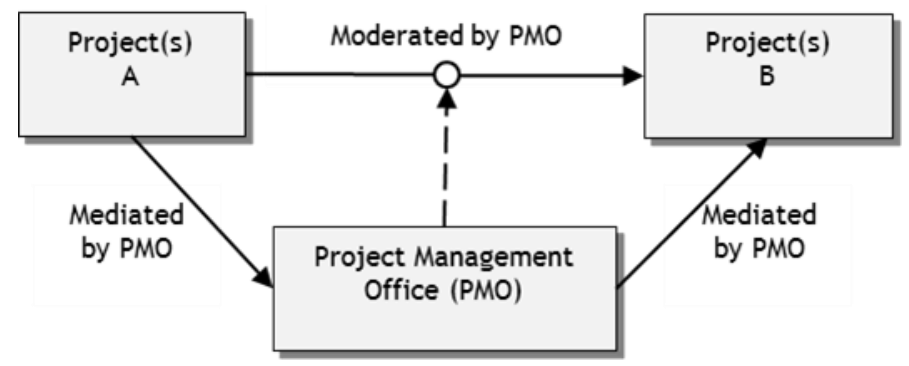

Figure 1: Knowledge transfer conceptual model [11] 
The moderating role involves the adoption of processes, systems, and tools to ensure that the appropriate knowledge is developed, stored, aligned, transferred, delivered, and used by the next project [11]. The mediating role, on the other hand, involves control of the characteristics of generated knowledge to ensure that the knowledge can then be effectively transferred to the next project. Central to the PMO are people, tools, routines, and systems, which are used to enable the knowledge transfer [11].

\subsection{Knowledge transfer boundaries}

Knowledge transfer can occur between different entities in a project organisation. These entities have different boundaries or interfaces that the knowledge must cross between the sender and the receiver. Typical boundaries would be between different project teams, between a project team and the client, or between a project team and third parties within or outside the organisation. According to Tshuma et al. [11], the PMO can play a very important role in knowledge transfer. The challenge then is how knowledge is transferred across the different boundaries in a project environment, and what role the PMO can play in improving this knowledge transfer across the different boundaries. The literature covers the inhibitors of knowledge transfer in great detail; this research looked at the inhibitors from the perspective of various stakeholders who define knowledge transfer processes across different boundaries.

\subsection{Knowledge transfer inhibitors}

Aspects or issues that affect the process of knowledge transfer are referred to as inhibitors. It is noted that many inhibitors, when adequately addressed, turn into enablers. According to Louw, Steyn and Van Waveren [14], corporate culture and human factors have the greatest impact on knowledge transfer. A total of 36 knowledge transfer inhibitors were identified in the literature.

\subsection{Document management system}

It is apparent that organisations must use information or knowledge from past experiences in order to benefit other projects; and if they are to operate efficiently, this information is typically stored in a data management system [15]. This illustrates the importance of an organisation's ability to harness and store information for future use. Information technology-based document management systems have brought about massive gains in respect of KT, in that it has become far easier to store large amounts of data and to search through these volumes of data and easily identify a specific document [16]. 'Document management systems' can be defined as the implementation of a comprehensive system that promotes the growth of an organisation's knowledge [17]. The most important aspects of a KT system are the people, the technology, and the processes applied in their environment [3].

Damodaran and Olphert [15] noted the following success factors for the successful implementation of a document management system:

- Speedy implementation;

- Integrated into ways of work;

- $\quad$ Lead and driven from the top;

- $\quad$ Properly aligned with all organisational initiatives;

- $\quad$ Simple and responsive system;

- $\quad$ Proper implementation of change management (communication, support, and training);

- $\quad$ Promotion of knowledge-sharing culture.

According to Ahmad et al. [18], Gomes, Oliveira and Chaves [19], and Offsey [20], the use of a document management system has resulted in some organisations realising the following benefits:

- Document-related cost reduction;

- Improved effectiveness and efficiency of work processes;

- $\quad$ Reduced activity turnaround time and level of effort required;

- Increased productivity and profitability;

- $\quad$ Easy access and availability of the knowledge to all individuals;

- Knowledge is available when needed without wasting time searching for it;

- $\quad$ Elimination of challenges associated with geographical distance.

However, document management systems have their own challenges in implementation. According to Ahmad et al. [18], some of the challenges that some organisations experience are the following: 
- $\quad$ The use of paper in parallel with an electronic document management system creates challenges relating to time and consistency;

- The difficulty in measuring the benefits of the system. It has been noted that organisations are reluctant to move to an electronic document management system because of the significant investment (cost and time) that is required, as well as the fact that benefits take time to be realised.

It has also been noted that technology is not necessarily the solution to all KT challenges, even though it is a key requirement. For a successful KT system, technology and measurement are needed along with leadership and an appropriate culture [20].

No indication was found in the literature about which inhibitors relate to specific boundaries in a project environment, nor about the significance of each inhibitor. It is likely that some inhibitors affect all boundaries, while other inhibitors would be specific to certain boundaries. Also, no indication was found in the literature of how the PMO might play a role in dealing with the inhibitors at specific boundaries.

Therefore this study focused on identifying the differences in KT processes across the different boundaries, the role that the PMO plays in KT across the different boundaries, and the inhibitors relevant to different boundaries. It emerged that, in the case organisation, the document management system is a key inhibitor of knowledge transfer, especially between two project teams. The role of the document management system was then further explored as a key inhibitor of knowledge transfer between two project teams.

\section{CONCEPTUAL MODEL}

Based on the literature review, the model in Figure 2 was proposed.

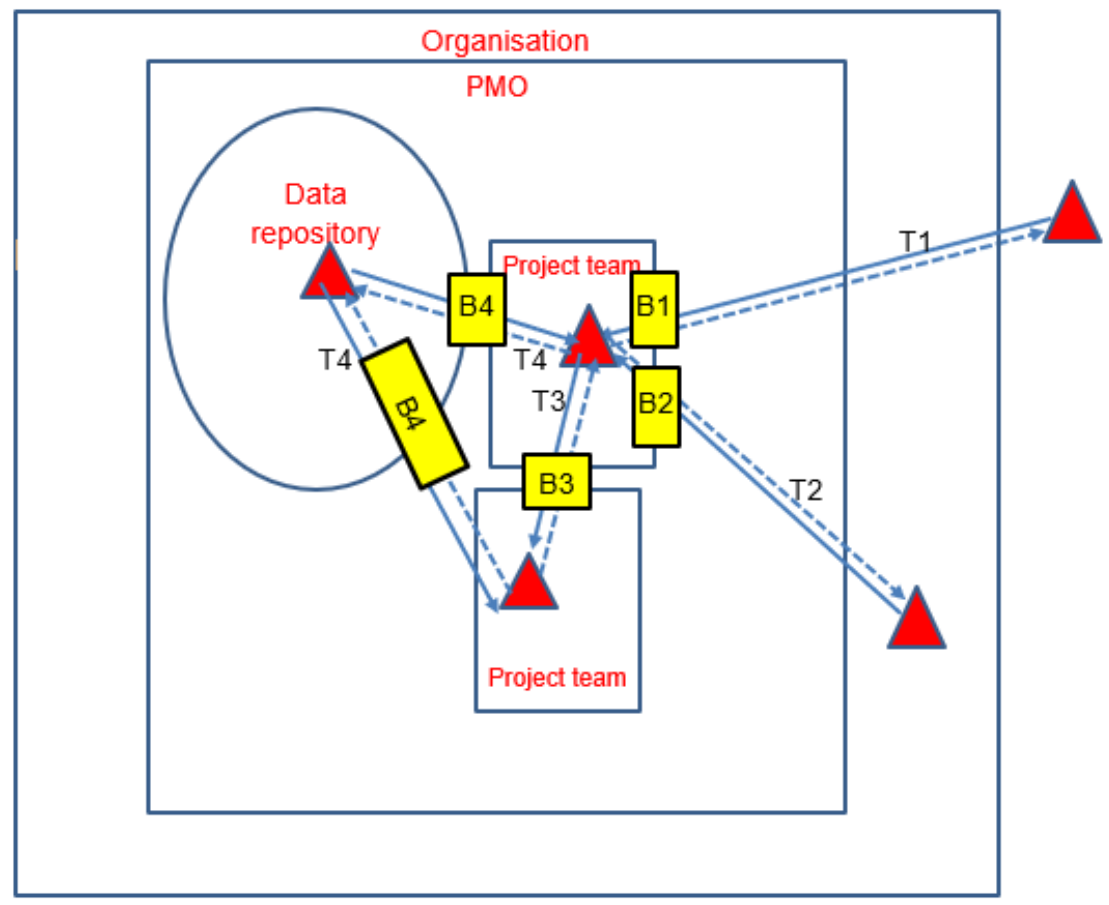

Figure 2: Research conceptual model

Key to Figure 2:

Knowledge asset, whether outside the organisation, in the organisation, in the PMO repository, or in a project team.

Knowledge transfer boundary that must be crossed to transfer knowledge asset from one entity to another.

Knowledge transfer in opposite directions. 
T1 Knowledge transfer from outside the organisation to a project team.

T2 Knowledge transfer between a project team and internal stakeholders.

T3 Knowledge transfer between two project teams in the PMO.

T4 Migration of knowledge to and from data repository.

Transfer boundaries

B1 Boundary between the project team and organisational environment (external stakeholders) where knowledge may be sourced or sent.

B2 Boundary between the internal stakeholders and the project team.

B3 Boundary between two project teams in the PMO.

B4 Boundary between project teams and the data repository.

\section{RESEARCH DESIGN AND METHODOLOGY}

\subsection{Research approach}

Based on the research objectives and questions, a single case study was conducted at a specific mine in Botswana. A case study method was considered appropriate, as case studies are used to investigate phenomena in real-life settings that give real-life explanations of what is happening [21]. In this study, the case method was used to find out how knowledge transfer takes place with regard to the mechanisms identified in the literature. Challenges with case study research have been noted - mainly the objectivity or thoroughness of the research and the generalisability of the results [21]; [22]. These challenges are addressed below.

\section{Generalisation}

Generalisation is the extent to which research outcomes are applicable outside of the sample population used for the research [22]. It is important because it establishes the extent to which research outcomes add to theory or knowledge. According to Yin [23], analytic generalisation typically applies to case studies, and study findings are generalised back to the theory established during the literature review. This study is exploratory, and aims at developing knowledge about differences in knowledge transfer across specific organisational boundaries. Analytic generalisation, was applied as the findings were analysed and related back to the literature.

\section{Construct validity}

This is the extent to which subjectivity is eliminated in the research [22]. This was achieved by designing questionnaires and tools that focused on objective answers (as opposed to subjective answers) as much as possible. As advised by Yin [23], all data in this study was properly recorded and filed, and the interview transcripts for the focus group, as well as the semi-structured interviews, were reviewed by the respondents before being finalised to ensure that the information was captured correctly. Subjectivity was therefore reduced and construct validity was improved.

\section{Internal validity}

This is the extent to which the research conclusively demonstrates causal relationships, thus validating a proposition [22]. Internal validity was achieved by ensuring the vigorous testing of causal relationships based on the literature, and testing all the outcomes against the literature, as proposed by Yin [23]. All outcomes were tested and related back to the relevant literature. Consistency between the research findings and the literature was found in this study.

\section{Reliability}

This is the extent to which the research results can be repeated by the researcher or another researcher, and it is confirmed by replication and consistency of results [22]. In this study, reliability was achieved by ensuring that all data records were properly recorded and filed, and that objective tools were used for the research. A protocol for the focus group discussion (described later) was developed, documented, and used during the session. A protocol for the semi-structured interviews (discussed later) was also developed, documented, and used for every interview. By documenting such protocols, it becomes easier to repeat the process in exactly the same way, which increases reliability [23].

\subsection{Research design}

Exploratory qualitative research was conducted using a case study. The research design outlined the process followed in order to gather and analyse data. 


\subsection{Data collection}

The following methods were used to collect data to answer the research questions. The primary data were collected through focus group workshops and semi-structured interviews.

\section{Focus group workshop}

The focus group technique was selected as the initial method of data gathering for this study in order to gain early insights into the topic. The focus group technique involves gathering a group of people who are knowledgeable about the topic, and creating a group discussion that is moderated or facilitated to discuss issues related to the topic, and to obtain information relevant to a study [24]. Like most research tools or techniques, the focus group technique has its own advantages and disadvantages [24].

\section{Advantages:}

It is an efficient way to collect data, as several people are engaged at the same time, and the data is gathered simultaneously.

The discussions can lead to energising the group, and so help to promote the further generation of ideas. There can be good interaction between the group members, which helps ideas to surface.

\section{Disadvantages:}

Sometimes the participation of group members may be affected, as some may not be comfortable in a group setting. The facilitator addressed this during the focus group session by continually monitoring the participation of all panel members, and encouraging those who were not talking to contribute to the discussions.

Sometimes there can be dominating individuals in the group, which can lead to biased or unrepresentative outcomes or a group effect. This was avoided in this study, as the facilitator ensured the active participation of all the panel members. After the discussion, all the panel members were required to write down their individual answers on 'sticky notes'. This ensured that all of the panel members were heard.

Focus group discussions tend to have open-ended questions in order to provoke discussion, and the researcher can lose control of the discussion if the group veers off topic. This was managed in the session by ensuring that the panel understood the context of the session through the presentation that was done at the beginning of the session. The facilitator also assisted during the discussion by reminding the team of the question when the discussion was going off track.

The key to a focus group discussion is that the facilitator is skilled enough to control the discussion [24].

Purposive sampling was used to identify participants to take part in the focus group discussion, as the researcher used his knowledge of the organisation to determine which participants would have adequate knowledge about the research area. The discussion was conducted to gain participants' understanding of how knowledge transfer takes place across the different boundaries, as well as understanding the knowledge transfer inhibitors in the project environment. A single focus group was established with participants from the PMO of the mining case studied. The focus group consisted of eight members who were all involved in projects at various levels in the organisation.

Participants were asked a series of questions about how knowledge transfer takes place across different boundaries. After being taken through an explanation of the possible role of the PMO, the participants were then asked to answer the same questions again. They were subsequently asked to write down as many knowledge transfer inhibitors as they could identify. The answers were displayed and read out to the participants. Finally, they were asked to write down the top five knowledge transfer inhibitors in the PMO.

\section{Semi-structured interviews}

Semi-structured interviews were conducted with seven people from the PMO, all in various roles in the $\mathrm{PMO}$, and all with knowledge of project information management and document management. The interviewees were all asked the following:

- $\quad$ Please describe the document management system used in the PMO.

- Who uses the system, and who has access to the system?

- How does the system work?

- $\quad$ How is the system managed?

- In your opinion, how effective is the document management system? 
- $\quad$ Please describe the KT culture in the PMO of the case organisation.

- $\quad$ Please explain the importance of the document management system in respect of KT in the PMO.

- $\quad$ Please explain to what extent the document management system is working in respect of KT in the PMO.

\subsection{Data analysis}

Thematic and content analysis were used as data analysis techniques, and Atlas.Ti software was used for the analysis of both the focus group outcomes and the outcomes of the semi-structured interviews.

\section{RESULTS}

\subsection{Knowledge transfer processes}

Based on the focus group outcomes, specific knowledge transfer processes were identified and their frequency of use across each of the boundaries being considered was assessed. Table 1 shows the processes identified and their frequency of use in terms of transfer across specific boundaries. Knowledge transfer processes were derived from the focused group session data, based on answers to the questions on the knowledge transfer processes.

Table 1: Knowledge transfer processes

\begin{tabular}{|c|c|c|c|c|c|}
\hline \multirow{2}{*}{$\begin{array}{l}\text { Knowledge } \\
\text { transfer } \\
\text { process }\end{array}$} & \multirow[b]{2}{*}{ Description } & \multicolumn{3}{|c|}{ Frequency } & \multirow[t]{2}{*}{ Sum } \\
\hline & & B1 & B2 & B3 & \\
\hline Discussions & $\begin{array}{l}\text { Discussions held between parties discussing project aspects, thus } \\
\text { sharing knowledge. }\end{array}$ & 7 & 4 & 2 & 13 \\
\hline Meetings & $\begin{array}{l}\text { Formal meetings held where knowledge is shared through project } \\
\text { discussions }\end{array}$ & 3 & 15 & 17 & 35 \\
\hline $\begin{array}{l}\text { Project } \\
\text { management } \\
\text { process }\end{array}$ & $\begin{array}{l}\text { Process used to conduct project management activities. The process } \\
\text { incorporates activities that promote KT and transfer. }\end{array}$ & 12 & 3 & 14 & 29 \\
\hline $\begin{array}{l}\text { Sharing } \\
\text { documents }\end{array}$ & $\begin{array}{l}\text { Sharing documents as a way of knowledge sharing, includes aspects of } \\
\text { reading and hence sharing knowledge. }\end{array}$ & 13 & 13 & 12 & 38 \\
\hline Training & Formal session held to teach or educate on specific topics. & 3 & 3 & 3 & 9 \\
\hline Retrospect & $\begin{array}{l}\text { Formal session held with project stakeholders to discuss lessons learnt, } \\
\text { and successes and failures. Includes the review of retrospective reports } \\
\text { from prior projects as a platform for learning. }\end{array}$ & 6 & 1 & & 7 \\
\hline Resourcing & $\begin{array}{l}\text { Resourcing in a way that swops members from different teams to share } \\
\text { knowledge across the teams. }\end{array}$ & 2 & 1 & & 3 \\
\hline Observations & $\begin{array}{l}\text { Knowledge shared through visual observation of how someone carries } \\
\text { out a certain activity. }\end{array}$ & 3 & 2 & & 5 \\
\hline
\end{tabular}

Key:

B1: Boundary between two project teams

B2: Boundary between a project and its internal stakeholders

B3: Boundary between a project team and its external stakeholders

Primary, key process

Primary and secondary key processes were defined for each boundary.

The results show that the predominant knowledge transfer processes across specific boundaries are:

Knowledge transfer between two project teams

\begin{tabular}{|l|l|}
\hline Dominant process & Sharing of documents \\
\hline Secondary process & Project management process \\
\hline
\end{tabular}


Therefore, for knowledge transfer between project teams, the ability to share documents is the most important. This means that the role of the PMO would be to ensure that it is easy and simple to share documents. This process would ensure that:

- $\quad$ the right documents are generated by each project team as they work;

- $\quad$ the documents are properly archived in a system where retrieval is easy for any other project team;

- $\quad$ other project teams have access to the archived information in order for them to be able to access the knowledge it contains.

This is in agreement with the mediating role defined by Tshuma et al. [11].

The secondary knowledge transfer process is the project management process. The role of the PMO in this case is to ensure that the project management system is established and mature enough to drive the practices that promote knowledge transfer. This includes ensuring that the project management processes drive the execution of activities such as knowledge-sharing workshops, participation in post-project reviews, or generating the right documents to the right standard for future knowledge sharing. Standardisation of processes between teams is also vital. This is in agreement with the mediating and moderating role defined by Tshuma et al. [11].

Knowledge transfer between the project team and internal stakeholders

\begin{tabular}{|l|l|}
\hline Dominant process & Meetings \\
\hline Secondary process & Sharing of documents \\
\hline
\end{tabular}

The most important knowledge transfer process between a project team and internal stakeholders is the meetings held. This is the platform where a project team discusses the project with the stakeholders. From a process point of view, the role of the PMO is to ensure that the meetings do take place and that the records are properly archived. This is aligned with the mediating and moderating roles defined by Tshuma et al. [11].

A secondary process is the sharing of documents; and again, as in sharing between two project teams, the PMO's role is to ensure that documents are generated, stored, and made available to other users. This is aligned with the mediating role as defined by Tshuma et al. [11].

Knowledge transfer between the project team and external stakeholders

\begin{tabular}{|l|l|}
\hline Dominant process & Meetings \\
\hline Secondary process & Project management processes \\
\hline
\end{tabular}

The most important knowledge transfer process between the project team and the external stakeholders is the meetings. The role of the PMO, again, is a process-defining role in ensuring that the necessary meetings do take place and that records are generated, stored, and available for future use. This is aligned with the mediating and moderating roles defined by Tshuma et al. [11].

A secondary process is the project management process. Again, the role of the PMO is to ensure that a systematic and mature project management process exists, and that it promotes knowledge transfer. This is aligned with the mediating and moderating role defined by Tshuma et al. [11].

It can be seen from these outcomes that different knowledge transfer processes are key to the different boundaries. From the analysis of the data (shown in Table 1), the overall dominant processes for knowledge transfer across the different boundaries in the case study PMO are meetings, sharing of documents, and the project management process.

\subsection{Knowledge transfer inhibitors}

As shown in Table 2 below, a total of 33 knowledge transfer inhibitors were identified through the focus group and interviews, compared with the 36 that were identified from the literature. Most of the inhibitors identified for the PMO case study were also found in the literature. The inhibitors that were not identified for the PMO related to physical distance, legal issues, and lack of a supportive performance management system. It could be argued that these particular inhibitors were not relevant or prominent in the PMO studied in the case organisation, owing to its localised operation. 
Table 2: Knowledge transfer inhibitors identified for the PMO

\begin{tabular}{|c|c|c|}
\hline No & Inhibitor & Literature reference \\
\hline 1 & Lack of recognition by supervisor of person sharing knowledge. & {$[13],[24],[25],[26]$} \\
\hline 2 & Job security - fear of losing the job once knowledge is shared. & {$[26]$} \\
\hline 3 & $\begin{array}{l}\text { Inadequate mode of communication - e.g. emailed reports not reaching all interested } \\
\text { parties. }\end{array}$ & [24], [13], [25], [26] \\
\hline 4 & $\begin{array}{l}\text { Lack of confidence / low self-esteem issues or inferiority complex leading to } \\
\text { unwillingness to share knowledge. }\end{array}$ & {$[26]$} \\
\hline 5 & Lack of team work, thus not sharing knowledge. & {$[13],[24],[25]$} \\
\hline 6 & Lack of desire to receive knowledge. & {$[26],[13],[24]$} \\
\hline 7 & Lack of desire to share knowledge. & {$[26],[13],[24]$} \\
\hline 8 & $\begin{array}{l}\text { Lack of employee engagement. No discussions between teams and management, thus } \\
\text { affecting knowledge sharing. }\end{array}$ & [13] \\
\hline 9 & $\begin{array}{l}\text { 'Me and them' syndrome; operating in a clique, and refusing to interact with those } \\
\text { not in your clique. }\end{array}$ & [13] \\
\hline 10 & $\begin{array}{l}\text { Misplaced competition - wanting to be the best by depriving others of useful } \\
\text { knowledge and experience. }\end{array}$ & [26] \\
\hline 11 & Cultural barriers - arising from people from different areas or countries. & [26] \\
\hline 12 & $\begin{array}{l}\text { Dysfunctional reporting structure - leading to lack of alignment and poor } \\
\text { communication in the teams. }\end{array}$ & [24], [13], [25] \\
\hline 13 & $\begin{array}{l}\text { Poor communication - not clearly detailing or stating the information to be shared } \\
\text { and the use of different languages. }\end{array}$ & [24], [26] \\
\hline 14 & $\begin{array}{l}\text { Inadequately structured platforms, lack of forums and gatherings or meetings where } \\
\text { people can share knowledge. }\end{array}$ & [13], [25] \\
\hline 15 & Project team members working in silos. & [27] \\
\hline 16 & Lack of proper documentation of project information. & [13] \\
\hline 17 & $\begin{array}{l}\text { Poor information sharing - no proper channels or system set up so that information } \\
\text { flows easily and everyone is aware of the channels. }\end{array}$ & [13] \\
\hline 18 & No culture of recording knowledge. & [13] \\
\hline 19 & Poor documentation and document control. & [13] \\
\hline 20 & $\begin{array}{l}\text { Inadequate document management system - the system does not meet the required } \\
\text { standard to ensure adequate knowledge management. }\end{array}$ & [13] \\
\hline 21 & $\begin{array}{l}\text { Silo mentality - project teams working in isolation and failing to share knowledge } \\
\text { with other teams or stakeholders. }\end{array}$ & [27] \\
\hline 22 & $\begin{array}{l}\text { Personality traits - unwillingness to share knowledge, driven by issues such as } \\
\text { jealousy, pride, or hatred. }\end{array}$ & [13], [24], [26] \\
\hline 23 & $\begin{array}{l}\text { Lack of skill or experience of team members, leading to their not being able to share } \\
\text { knowledge out of fear and lack of knowledge. }\end{array}$ & No \\
\hline 24 & $\begin{array}{l}\text { Inefficiency of project team members. Failing to work correctly - that is, not doing } \\
\text { things the right way. }\end{array}$ & No \\
\hline 25 & Lack of resources - whether time, tools, budget, or facilities. & [24], [26] \\
\hline 26 & $\begin{array}{l}\text { Knowledge is power - desire to be influential and powerful by being deemed } \\
\text { knowledgeable, thus denying others knowledge. }\end{array}$ & {$[13],[24],[26]$} \\
\hline 27 & $\begin{array}{l}\text { Lack of senior leadership support. Leadership does not emphasise the importance of } \\
\text { knowledge management or support the activities. }\end{array}$ & [13], [24], [25] \\
\hline 28 & Lack of trust between people, leading to reluctance to share knowledge. & [13], [24], [25] \\
\hline 29 & Job security - fear of losing the job if others know what you know. & [26] \\
\hline 30 & $\begin{array}{l}\text { Poor professional or social relationships that lead to failure to share and communicate } \\
\text { effectively. }\end{array}$ & [13], [25] \\
\hline 31 & Hidden agenda - people not working openly and wanting others to fail. & [13] \\
\hline 32 & $\begin{array}{l}\text { Distance factor - challenges arising from people not being in the same geographical } \\
\text { space, making it difficult to communicate. }\end{array}$ & [24], [26] \\
\hline 33 & $\begin{array}{l}\text { Culture of seniority. Working environment where it is assumed that the more senior } \\
\text { person knows more than the junior person. }\end{array}$ & [24], [13] \\
\hline
\end{tabular}

Inhibitors that were not found in the literature were:

- $\quad$ the inexperience of project teams, and

- the inefficiency of project team members.

\section{Ranking of knowledge transfer inhibitors for PMO}

Figure 3 shows the inhibitors based on their ranking, derived from the focused group discussion. The panel ranked the inhibitors, identifying those that each panellist felt had most impact on the PMO. 


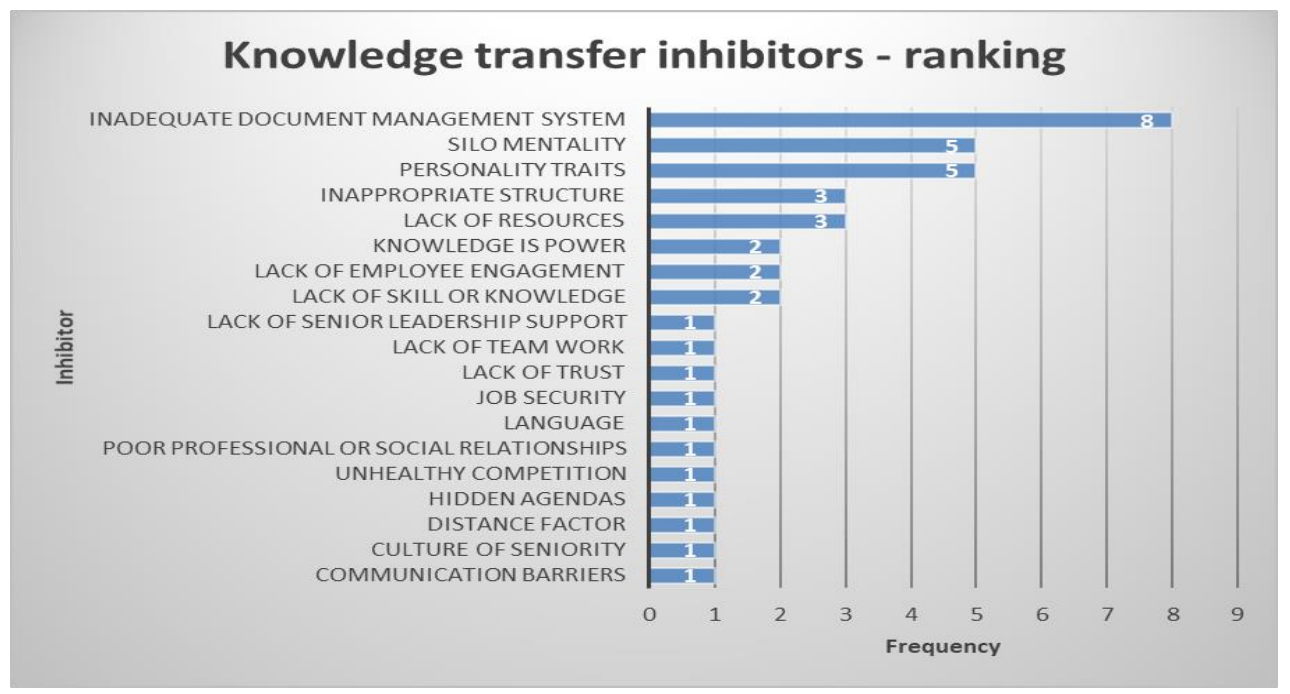

Figure 3: Knowledge transfer inhibitors - ranked for PMO

According to Louw, Steyn and Van Waveren [14], corporate culture and human factors had the greatest impact on knowledge transfer. However, the surprising outcome of this study was that the inadequacy of the document management system was ranked as the greatest hindrance to knowledge transfer. Based on this ranking of knowledge transfer inhibitors, the study focused on assessing the role of the document management system in knowledge transfer. The next-highest inhibitors were personality traits and silo mentality. These were consistent with the literature [14].

\subsection{Document management system}

The following themes were identified from the data and then analysed:

\section{System setup}

It was established that the system setup has the following features:

\section{System access}

The system is accessible to all PMO team members, and the system has access control and different level rights that are given to different project team members.

\section{System management}

The system has a dedicated resource to control and manage its use. This role is important in order to train new users, set up new projects, check compliance of documents with requirements and standards, and reporting.

\section{System structure}

The filing system in the document management system is hierarchical and structured so that it is aligned with the functional structure of the organisation, making it easy to search and look for documents.

\section{System use and effectiveness}

Importance of the document management system:

There was unanimous agreement about the importance of the document management system for KT; it is a platform that drives KT in the PMO. The key system features are:

- $\quad$ storage of project information for future use and learning;

- $\quad$ that it should be the only repository for information and hence source of knowledge;

- $\quad$ that it provides a fall back and prevents re-inventing the wheel;

- $\quad$ that it provides security for organisational assets (knowledge).

\section{Knowledge management culture}

The KT culture in the PMO is elementary. There is no appreciation of the importance of KT or the potential benefits, and the PMO teams tend to operate in their team silos. 


\section{Mandatory system}

Although the system is mandatory, this is not enforced, which has compromised the effectiveness of the system. The availability of alternative storage facilities, such as computer hard drives or shared folders, has also reduced the effective use of the system.

\section{Summary - System effectiveness}

The main reasons why the PMO system in the case is not fully effective are that:

- $\quad$ the people are not using the system as much as they could because they have alternatives, such as the shared folders and their computer hard drives;

- $\quad$ there is no enforcement, and there are no consequences for non-compliance;

- $\quad$ the appreciation of the need for KT is still low in the PMO teams;

- $\quad$ the use of the system at the moment is down to personal discipline.

There was agreement between the research participants that the system, although officially mandatory, was not enforced, and that this was compromising the effectiveness of the system.

\section{CONCLUSIONS AND RECOMMENDATIONS}

Conclusions about the first objective - the investigation of KT mechanisms across different boundaries are addressed next. This is followed by conclusions about the second objective - the identification of factors inhibiting KT across the different boundaries. The importance of a document management system emerged during the study as the most significant inhibitor of KT, and conclusions about this are also made.

\subsection{Discussion of results, and conclusions}

\subsubsection{Knowledge transfer across different boundaries in a project environment}

Different KT processes are applicable to KT across different boundaries; and there are different key processes at play across different boundaries. The PMO can and should be set up to recognise the different boundaries and the key processes at each boundary so that the processes relevant to each boundary are deliberately set up to promote KT. The key processes in this PMO are summarised in Table 3.

Table 3: Key processes in the PMO

\begin{tabular}{|l|l|l|}
\hline Boundary & Key knowledge transfer process & PMO role \\
\hline \multirow{2}{*}{ Between two project teams } & Sharing documents & Mediation \\
\cline { 2 - 3 } & Project management process & Mediation and moderation \\
\hline \multirow{2}{*}{$\begin{array}{l}\text { Between project team and internal } \\
\text { stakeholders }\end{array}$} & Meetings & Mediation and moderation \\
\cline { 2 - 3 } $\begin{array}{l}\text { Between project team and external } \\
\text { stakeholders }\end{array}$ & Sharing documents & Mediation \\
\cline { 2 - 3 } & Project management process & Mediation and moderation \\
\cline { 2 - 3 }
\end{tabular}

What is evident from the research is that different processes are used for KT across the different boundaries. However, the identified key processes cannot be generalised to other PMOs or project environments, as other factors may be influencing the knowledge transfer, which may lead to different key processes. It is worth noting that, with the different processes at play, this calls for the specific management of KT based on the boundaries to be crossed and irrespective of the nature of the process. It is also important to recognise that there are different processes and that they should be managed accordingly. The conceptual model is updated, as shown in Figure 4.

As illustrated by the conceptual model in Figure 4, there are specific knowledge transfer processes across each of the boundaries; and these, based on the research, can be addressed individually to enhance KT. It is important for any project environment to identify the key processes in P1, P2, and P3, as they are applicable to that particular scenario or situation, and to address the requirements for efficient and effective KT. 


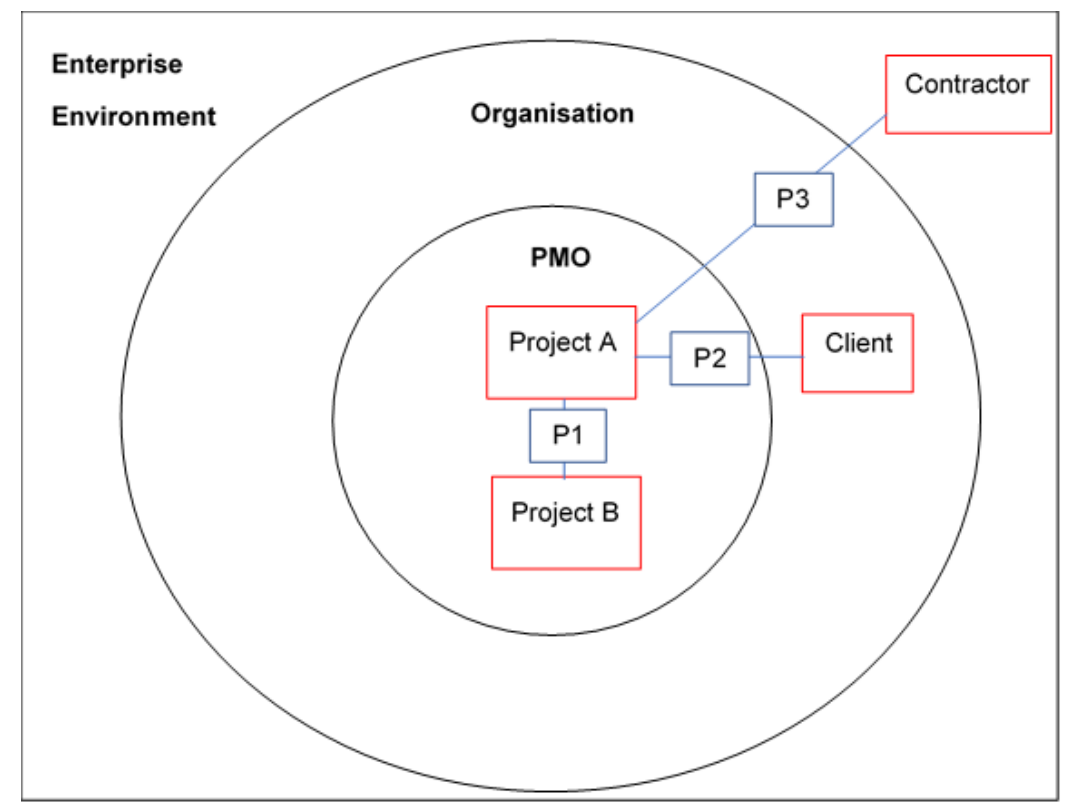

Figure 4: Updated knowledge transfer processes model

Key:

Knowledge sources - project A, project B, client, contractor

Knowledge transfer processes

P1 - Transfer between two project teams. Key processes in the PMO are the sharing of documents and the project management process

P2 - Transfer between project team and internal stakeholder. Key processes in the PMO are meetings and the sharing of documents

P3 - Transfer between project team and external stakeholders. Key processes in the PMO are meetings and the project management process

\subsubsection{Knowledge transfer inhibitors}

The PMO is largely affected by the inhibitors of KT identified in the literature. However, in terms of ranking, the PMO in the case considers the inadequacy of the document management system to be the most significant KT inhibitor, followed by behavioural aspects such as a silo mentality and personality traits. The most prominent inhibitor, an inadequate document handling system, is contrary to the finding of Louw et al. [14] that the most influential KT inhibitors are corporate culture and other human factors. This contradiction may arise from the fact that, according to the respondents in the case studied, the document management system is not used optimally. The main business of the case studied is a mining operation, not project management; while Louw et al. [14] studied a well-established project management organisation that in all likelihood has a very well-established document control system. It could be argued, however, that the challenges with the document management system emanate from corporate culture and human factors. The knowledge-sharing culture in the organisation, according to the research, is not mature, and thus people are not complying with the requirements of document management. The system lacks support from leadership, and human factors include that people resist new systems and only do enough to comply. It is also evident that people in this PMO work in silos. Therefore, although the inadequacy of the document management system was identified as the top inhibitor for the PMO, it can be deduced that the root causes correspond with the findings of Louw et al. [14]. However, the findings also underline the importance of the document management system in KT.

\subsubsection{Document management system}

The outcome of the research was that the most significant KT inhibitor is the inadequate document management system. The following conclusions are made: 
- The document management system is a very important part of the KT system in the PMO, and is key in ensuring effective KT. It is concluded that the document management system is vital for project organisations to support a KT system in the current business environment.

- $\quad$ Given the volumes of data typically handled in project environments, the document management system allows easy handling and sharing of documents, and so enhances knowledge sharing.

Damodaran and Olphert [15] identified some key requirements for setting up a successful document management system:

- The system has to be set up in a mature KT culture for the organisation. If the culture is immature, then the system will not be used effectively, as people do not appreciate the importance of KT.

- The system has to be driven from the top. It is important for senior leadership to demonstrate the importance of the system so that the work force can follow.

- $\quad$ There should be only one system that is used for document storage. The presence of alternative systems, such as shared folders and hard drives, causes people to pick and choose where to file documents according to what they find easier.

- $\quad$ The use of a single system should be compulsory for all project teams. As one interviewee participant put it, "If it is not in Eb [the document management system], it does not exist".

- $\quad$ The system should be simple and easy to use, and accessible to all employees.

- The system should be set up in alignment with the organisational projects setup for ease of use and for monitoring and reporting processes.

The conceptual model in Figure 5 has been developed for the document management system in the PMO setup:

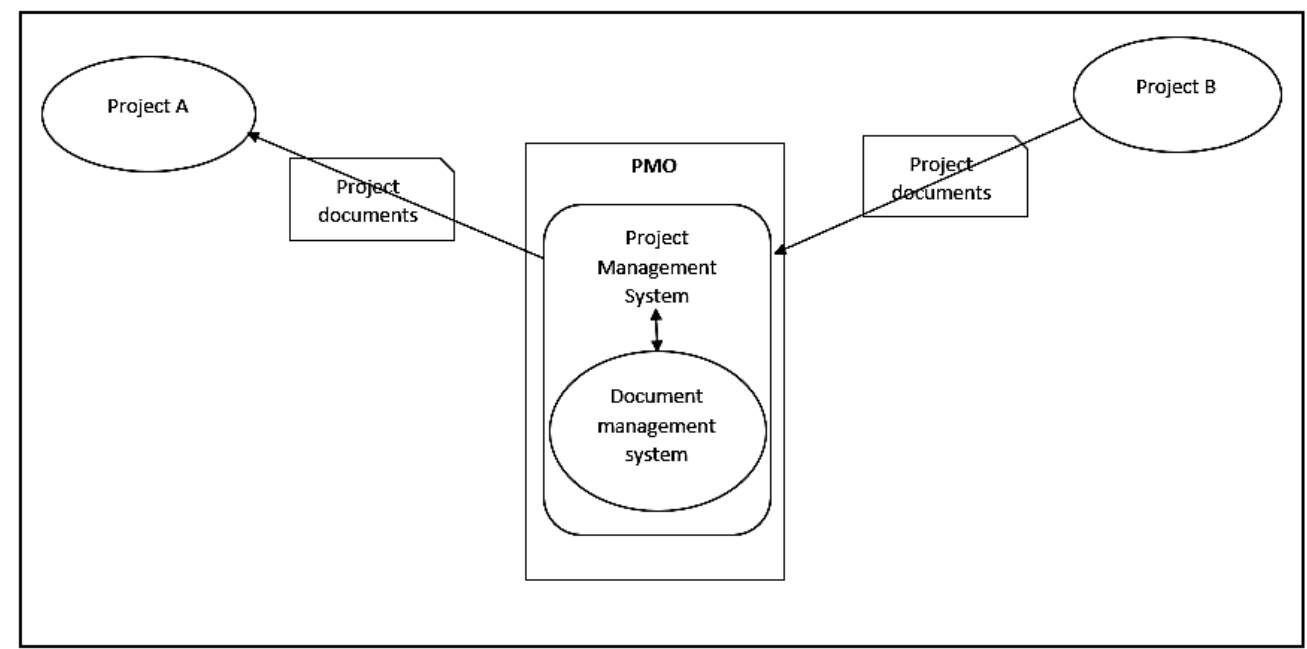

Figure 5: Document management system for transferring knowledge from project $B$ to project $A$ through the PMO.

As shown in the conceptual model in Figure 5, the document management system is an integral part of the PMO, and supports the project management processes with all documents having to go through the system. Project Team B generates project documents that are archived in the document management system and then accessed by Project Team A. Once properly set up, the document management system can act as the hub for KT for the organisation, with all documents flowing through the system for archiving and retrieval. This will go a long way in supporting an effective KT system; and if this is coupled with the right culture, KT maturity can be improved.

\subsection{Recommendations}

The case study was conducted on a specific PMO in a Botswana mining organisation. The usual challenges of generalisation for case research study also applied to this research. Although the study outcomes linked well with existing theory, further work would be required to explore knowledge transfer across different boundaries in a wider population of project environments in order to validate the outcomes from this specific case study. It is apparent that knowledge transfer processes will vary across different project 
environments; and the study does not imply generalisation to any other environment. It would be interesting, however, to investigate any variations of these processes across different project environments. It is therefore recommended that knowledge transfer across different boundaries, as well as the role of document management systems, be investigated further.

\section{REFERENCES}

[1] Brelade, S. \& Harman, C. 2003. A practical guide to knowledge management: A special commissioned report. London: Thorogood.

[2] Hanisch, B., Lindner, F., Mueller, A. \& Wald, A. 2009. Knowledge management in project environments. J. Knowl. Manag., 13(4), pp. 148-160, doi: 10.1108/13673270910971897.

[3] Sokhanvar, S., Matthews, J. \& Yarlagadda, P. 2014. Importance of knowledge management processes in a projectbased organization: A case study of research enterprise. In Global Congress on Manufacturing and Management, Procedia Engineering, 97, pp. 1825-1830, doi: 10.1016/j.proeng.2014.12.336

[4] Project Management Institute. 2017. A guide to the project management body of knowledge (PMBOK guide), $6^{\text {th }}$ ed. Newton Square, Pennsylvania: Project Management Institute.

[5] Schindler, M. \& Eppler, M. J. 2003. Harvesting project knowledge: A review of project learning methods and success factors. Int. J. Proj. Manag., 21(3), pp. 219-228.

[6] Nicholas, J. M. \& Steyn, H. 2021. Project management for engineering, business and technology. $6^{\text {th }}$ ed. London \& New York: Routledge.

[7] Kotnour, T. \& Vergopia, C. 2005. Learning-based project reviews: Observations and lessons learned from the Kennedy Space Center. EMJ - Eng. Manag. J., 17(4), pp. 30-38, doi: 10.1080/10429247.2005.11431670.

[8] Von Zedtwitz, M. 2002. Organizational learning through post-project reviews in R\&D. R D Manag., 32(3), pp. 255268, doi: $10.1111 / 1467-9310.00258$.

[9] Keegan, A. \& Turner, J. R. 2001. Quantity versus quality in project-based learning practices. Manag. Learn., 32(1), pp. 77-98, doi: 10.1177/1350507601321006.

[10] Lehtimäki, T., Simula, H. \& Salo, J. 2009. Applying knowledge management to project marketing in a demanding technology transfer project: Convincing the industrial customer over the knowledge gap. Elsevier Ind. Mark. Manag., 38, pp. 228-236.

[11] Tshuma, B., Steyn, H. \& Van Waveren, C. 2018. The role played by PMOs in the transfer of knowledge between projects: A conceptual framework. South African Journal Ind. Eng., 29(2), pp. 127-140.

[12] Van Waveren, C. C., Oerlemans, L. A. G. \& Pretorius, M. W. 2014. Knowledge transfer in project-based organizations: A conceptual model for investigating knowledge type, transfer mechanisms and transfer success. In IEEE International Conference on Industrial Engineering and Engineering Management, IEEE IEEM, pp. 1176-1181, doi: 10.1109/IEEM.2014.7058824.

[13] Zaim, H., Gürcan, Ö. F., Tarım, M., Zaim, S. \& Alpkan, L. 2015. Determining the critical factors of tacit knowledge in service industry in Turkey. Procedia - Soc. Behav. Sci., 207, pp. 759-767, doi: 10.1016/j.sbspro.2015.10.156.

[14] Louw, I., Steyn, H. \& Van Waveren, C. 2017. Inhibitors to the transfer of knowledge generated on projects: A case study in a construction company. Journal of Contemporary Management, 14(1), pp. 986-1010.

[15] Damodaran, L. \& Olphert, W. 2000. Barriers and facilitators to the use of knowledge management systems. Behav. Inf. Technol., 19(6), pp. 405-413, doi: 10.1080/014492900750052660.

[16] Córdova, F. M., \& Gutiérrez, F. A. 2018. Knowledge management system in service companies. Procedia Comput. Sci., 139, pp. 392-400.

[17] Salisbury, M. W. 2003. Putting theory into pr actice to build knowledge management systems. J. Knowl. Manag., 7(2), pp. 128-141, doi: 10.1108/13673270310477333.

[18] Ahmad, H. S., Bazlamit, I. M. \& Ayoush, M. D. 2016. Investigation of document management systems in small size construction companies in Jordan. In $7^{\text {th }}$ International Conference on Engineering, Project and Production Management, Procedia Engineering 182, pp. 3-9. doi: 10.1016/j.proeng.2017.03.101

[19] Gomes, F., Oliveira, M. \& Chaves, M. S. 2018. An analysis of the relationship between knowledge sharing and the project management process groups. Knowl. Process Manag., 25(3), pp. 168-179, doi: 10.1002/kpm.1578.

[20] Offsey, S. 1997. Knowledge management: Linking people to knowledge for bottom line results. J. Knowl. Manag., 1(2), pp. 113-122, doi: 10.1108/EUM0000000004586.

[21] Saunders, M. N. K., Lewis, P. \& Thornhill, A. 2016. Research methods for business students, $7^{\text {th }}$ ed. Harlow: Pearson.

[22] Rowley, J. 2002. Using case studies in research. Manag. Res. News, 25(1), pp. 16-27.

[23] Yin, R. K. 2014. Case study research: Design and methods $5^{\text {th }}$ ed. California. Thousand Oaks.

[24] Barry, M.-L., Steyn, H. \& Brent, A. 2009. The use of the focus group technique in management research: The example of renewable energy technology selection in Africa. J. Contemp. Manag., 6, pp. 229-240.

[25] Bagheri, S., Kusters, R.J., Trienekens, J. J. M. \& Van der Zandt, H. V. N. 2016. Classification framework of knowledge transfer issues across value networks. Procedia CIRP, 47, pp. 382-387.

[26] Kathiravelu, S. R., Mansor, N. N. A., Ramayah, T. \& Idris, N. 2013. Why organisational culture drives knowledge sharing. In International Conference on Innovation, Management and Technology Research, Procedia - Social and Behavioral Sciences, 129, pp. 119-126, doi: 10.1016/j.sbspro.2014.03.656.

[27] Lin, C., Wu, J. \& Yen, D. 2011. Exploring barriers to knowledge flow at different knowledge management maturity stages. Inf. Manag., 49, pp. 10-23.

[28] Lindner, F. \& Wald, A. 2011. Success factors of knowledge management in temporary organizations. Int. J. Proj. Manag., 29(7), pp. 877-888, doi: 10.1016/j.ijproman.2010.09.003. 